\title{
O teste de frio sem solo em sementes de abóbora
}

\author{
The modified cold germination test in squash seeds
}

\author{
Derblai Casaroli ${ }^{1}$ Danton Camacho Garcia ${ }^{2}$ Nilson Lemos de Menezes $^{3}$ \\ Marlove Fátima Brião Muniz ${ }^{4}$ Carlos André Bahry ${ }^{5}$
}

\begin{abstract}
Este trabalho teve como objetivo determinar o período de exposição à baixa temperatura no teste de frio sem solo, para avaliação de diferentes potenciais fisiológicos em lotes de sementes de abóbora. Foram avaliados seis lotes de sementes de abóbora cultivar "Menina Brasileira" (Cucurbita moschata Duch.) produzidas na safra 2003/2004. As sementes foram submetidas a diferentes períodos (três, cinco, sete e nove dias) de exposição à baixa temperatura para condução do teste de frio sem solo, a uma temperatura constante de $10^{\circ} \mathrm{C}$. Utilizou-se o delineamento inteiramente casualizado, em que os tratamentos constituíram um fatorial $6 x 4$ (seis lotes e quatro períodos de exposição), com quatro repetições de 50 sementes. As médias foram comparadas pelo teste de Tukey em nível de $5 \%$ de probabilidade de erro. Realizou-se também o teste de correlação simples de Pearson. Os resultados permitiram concluir que o período de três dias de exposição à baixa temperatura foi o mais indicado para a condução do teste de frio sem solo em sementes de abóbora.
\end{abstract}

Palavras-chave: Cucurbita moschata Duch., testes de vigor, potencial fisiológico.

\section{ABSTRACT}

This research was aimed at determining the exposition period at low temperature in the modified cold germination test, to evaluate physiological potential of squash seed lots. Six seed lots of squash, variety Menina Brasileira (Cucurbita moschata Duch.), produced in 2003/2004, were submitted at different exposition times for the development of the cold test. The modified cold gernation test was carried out at $10^{\circ} \mathrm{C}$ of constant temperature, during exposition time of three, five, seven and nine days. A completely randomized desing was used to the cold test, 0 constituting a factorial $6 \times 4$, corresponding to the six seed lots and four exposition time (3, 5,7 , and 9 days), with four repetitions. The averages were compared by the Tukey test, at 5\% of probability. The correlation test of Person ( $r$ ) was used too. For the modified cold germination test, the period of three days was the most indicated to evaluate the physiological potential of squash seeds.

Key words: Cucurbita moschata Duch., vigour tests, physiological potential.

$\mathrm{Na}$ atualidade, um dos aspectos de maior interesse, quando se avalia a qualidade fisiológica das sementes, refere-se à obtenção de resultados confiáveis em período de tempo relativamente curto. Assim, é crescente o interesse na utilização de testes de vigor no controle interno da qualidade, completando as informações do teste de germinação, com objetivo de obter parâmetros mais sensíveis para seleção dos melhores lotes de sementes (DIAS et al., 2001; RODO \&MARCOS FILHO, 2003).

A avaliação do vigor, apesar de fundamental para caracterizar a qualidade fisiológica das sementes,

\footnotetext{
${ }^{1}$ Departamento de Produção Vegetal, Escola Superior de Agricultura Luiz de Queiroz (ESALQ), Universidade de São Paulo (USP), Piracicaba, SP, Brasil.

${ }^{2}$ Departamento de Fitotecnia, Centro de Ciências Rurais (CCR), Universidade Federal de Santa Maria (UFSM), 97105-900, Santa Maria, RS, Brasil. E-mail: danton@ccr.ufsm.br. Autor para correspondência.

${ }^{3}$ Departamento de Fitotecnia, CCR, UFSM, Santa Maria, RS, Brasil.

${ }^{4}$ Departamento de Defesa Fitossanitária, CCR, UFSM, Santa Maria, RS, Brasil.

${ }^{5}$ Curso de Agronomia, UFSM, CCR, Santa Maria, RS, Brasil
} 
ainda necessita avançar, principalmente, em termos de padronização dos procedimentos para os testes utilizados (PÁDUA, 1998). Uma das hortaliças que necessita de maiores estudos dos testes para avaliação de sua qualidade fisiológica é a abóbora.

Dentre os testes mais indicados para compor um programa de qualidade de sementes de hortaliças, está o teste de frio (MARCOS FILHO, 2001), o qual verifica o desempenho quanto ao crescimento e desenvolvimento de plântulas normais, de lotes de sementes semeadas sob condições de baixa temperatura. Entretanto, para a maioria das sementes de hortaliças, como a abóbora, há necessidade de padronização dos parâmetros utilizados para a avaliação do vigor por meio desse teste.

O presente estudo teve como objetivo determinar o período de exposição à baixa temperatura no teste de frio sem solo, para identificar os diferentes potenciais fisiológicos de lotes de sementes de abóbora e sua correlação com outros testes de vigor.

A pesquisa foi desenvolvida no Laboratório Didático e de Pesquisa em Sementes do Departamento de Fitotecnia da Universidade Federal de Santa Maria (UFSM), Santa Maria, RS. Foram utilizados seis lotes de sementes de abóbora (Cucurbita moschata Duch.) cultivar "Menina Brasileira" produzidos na safra 2003/ 2004.

As sementes foram submetidas às seguintes determinações: grau de umidade, conduzido em estufa a $105 \pm 3^{\circ} \mathrm{C}$ por 24 horas (BRASIL,1992); teste de germinação, realizado com oito repetições de 50 sementes semeadas em rolos de papel de filtro umedecidos com água destilada, na proporção de 2,5 vezes a massa do papel seco. Além disso, os rolos contendo as sementes foram colocados em germinador regulado à $25^{\circ} \mathrm{C}$ (BRASIL,1992). A primeira contagem de germinação foi realizada conjuntamente com o teste de germinação, computando-se as plântulas normais verificadas na primeira contagem do teste de germinação, no quarto dia após a semeadura (BRASIL, 1992). O índice de velocidade de germinação foi realizado com oito repetições de 50 sementes, semeadas em rolos de papel de filtro umedecidos com água destilada na proporção de 2,5 vezes a massa do papel seco. Os rolos contendo as sementes foram colocados em germinador regulado a $25^{\circ} \mathrm{C}$, permanecendo até estabilizar o aparecimento de sementes germinadas (raiz primária visível). As avaliações foram realizadas diariamente, à mesma hora, a partir do dia em que surgiram as primeiras emissões de radículas germinadas. Calculou-se o índice de velocidade de germinação conforme MAGUIRE (1962). O envelhecimento acelerado foi conduzido em caixas plásticas de germinação usadas como mini-câmaras. Utilizou-se $20 \mathrm{~g}$ de sementes em duas subamostras, cada uma distribuída uniformemente, de maneira a formar uma camada simples sobre a superfície de tela metálica suspensa no interior da caixa plástica, as quais continham $40 \mathrm{ml}$ de água destilada, obtendo-se aproximadamente $100 \%$ de umidade relativa do ar. As caixas permaneceram em uma incubadora por um período de 48 horas, à temperatura de $41^{\circ} \mathrm{C}$. Ao término desse período, as sementes foram colocadas para germinar, conforme descrito anteriormente no teste de germinação, porém contendo quatro repetições de 50 sementes, efetuando-se a contagem única das plântulas normais aos seis dias após a semeadura. Quanto à emergência de plântulas, a semeadura foi realizada, aleatoriamente, em bandejas de isopor com 128 células, contendo substrato organo-mineral (PLANTMAX HA $^{\circledR}$ ). As bandejas foram mantidas em piscina hidropônica, em estufa plástica, por um período de sete dias após a semeadura, com temperatura média de $26,02^{\circ} \mathrm{C}$, em solução nutritiva proposta por CASTELLANE \&ARAUJO(1994), diluída a 50\%. Foram utilizadas quatro repetições de 50 sementes, sendo as avaliações realizadas aos sete dias após a semeadura. $\mathrm{O}$ teste de frio sem solo foi realizado com quatro repetições de 50 sementes, de forma semelhante ao teste de germinação. Em seguida, os rolos foram acondicionados em sacos plásticos vedados com fita adesiva, permanecendo por períodos de três, cinco, sete e nove dias em câmara à temperatura constante de $10^{\circ} \mathrm{C}$. Após esses períodos, os rolos foram colocados em germinador a $25^{\circ} \mathrm{C}$, durante seis dias, considerandose, na avaliação, somente plântulas normais.

O delineamento experimental utilizado, para o teste de frio sem solo, foi o inteiramente casualizado, em que os tratamentos constituíram um fatorial $6 \times 4$, correspondendo aos seis lotes de sementes e quatro períodos de exposição à baixa temperatura, com quatro repetições. Para os demais testes de avaliação da qualidade fisiológica, utilizou-se o mesmo delineamento experimental e o mesmo número de repetições. As médias foram comparadas pelo teste de Tukey em nível de 5\% de probabilidade de erro. Aplicouse também o teste de correlação linear simples de Pearson (r). Os dados relativos às variáveis expressas em percentagem foram previamente submetidos à transformação arco seno $(\mathrm{x} / 100)^{1 / 2}$ (STORCK et al., 2000).

Na tabela 1, são apresentados os valores obtidos nos testes de germinação, a primeira contagem de germinação, a velocidade de germinação, o envelhecimento acelerado e a emergência de plântulas. Verificou-se que as maiores médias foram obtidas no 
Tabela 1 - Resultados de grau de umidade das sementes (GU) e testes de germinação (TG), de primeira contagem de germinação (PC), de índice de velocidade de germinação (IVG), de envelhecimento acelerado (EA), de emergência de plântulas (EM), teste de frio (TF) (3, 5, 7 e 9 dias) e coeficientes de correlação (r) de seis lotes de sementes de abóbora. Santa Maria, RS, 2005.

\begin{tabular}{|c|c|c|c|c|c|c|c|c|c|c|}
\hline \multirow{2}{*}{ Lotes } & \multirow{2}{*}{ GU } & \multirow{2}{*}{ TG } & \multirow{2}{*}{$\mathrm{PC}$} & \multirow{2}{*}{ IVG } & \multirow{2}{*}{ EA } & \multirow{2}{*}{ EM } & \multicolumn{4}{|c|}{ Teste de frio } \\
\hline & & & & & & & 3 & 5 & 7 & 9 \\
\hline & ------- & ---- & - & ------- & $-\cdots$ & - & $\%$ & - n & - & ------ \\
\hline 1 & 8,4 & $60 c^{1}$ & $36 b$ & $17,5 \mathrm{~d}$ & $37 \mathrm{c}$ & $57 \mathrm{c}$ & $67 b c$ & $52 b$ & $54 a$ & $53 \mathrm{a}$ \\
\hline 2 & 8,3 & $80 \mathrm{ab}$ & $54 a$ & $19,7 \mathrm{~cd}$ & $57 \mathrm{a}$ & $69 \mathrm{ab}$ & $83 a b$ & $59 \mathrm{ab}$ & $55 \mathrm{a}$ & $56 a$ \\
\hline 3 & 6,5 & $71 b c$ & $36 b$ & $17,1 d$ & $42 c$ & $51 d$ & $75 b$ & $57 \mathrm{ab}$ & $51 \mathrm{ab}$ & $52 \mathrm{a}$ \\
\hline 4 & 6,7 & $77 \mathrm{ab}$ & $38 b$ & $18,2 \mathrm{~cd}$ & $38 \mathrm{c}$ & $66 b$ & $78 \mathrm{ab}$ & $59 \mathrm{ab}$ & $56 a$ & $55 \mathrm{a}$ \\
\hline 5 & 8,3 & $80 \mathrm{ab}$ & $63 a$ & $20,2 b$ & $51 b$ & $62 \mathrm{bc}$ & $82 a$ & $65 a$ & $57 a$ & $54 a$ \\
\hline 6 & 8,2 & $87 \mathrm{a}$ & $66 a$ & $22,9 a$ & $58 \mathrm{a}$ & $73 a$ & $87 a$ & $67 a$ & $57 \mathrm{a}$ & $56 a$ \\
\hline \multirow[t]{6}{*}{$\mathrm{CV}(\%)$} & & 9,22 & 11,99 & 6,83 & 4,25 & 7,22 & ------. & -------7 & ------. & ------- \\
\hline & TG (r) & - & & & & & $0,92 *$ & $0,55^{*}$ & $0,38 *$ & $0,57 *$ \\
\hline & $\mathrm{PC}(\mathrm{r})$ & $0,73^{*}$ & - & & & & $0,64 *$ & $0,56^{*}$ & $0,49 *$ & $0,39 *$ \\
\hline & IVG(r) & $0,61 *$ & $0,78^{*}$ & - & & & $0,59 *$ & $0,71^{*}$ & $0,43^{*}$ & $0,52 *$ \\
\hline & $\mathrm{EA}(\mathrm{r})$ & $0,56^{*}$ & $0,65^{*}$ & $0,66^{*}$ & - & & $0,54 *$ & $0,62 *$ & $0,49 *$ & $0,51 *$ \\
\hline & $\operatorname{EM}(r)$ & $0,46^{\mathrm{ns}}$ & $0,51 *$ & $0,56^{*}$ & $0,62 *$ & - & $0,52 *$ & $0,58^{*}$ & $0,44 *$ & $0,47 *$ \\
\hline
\end{tabular}

Médias não seguidas pela mesma letra em cada coluna diferem entre si pelo teste de Tukey em nível de 5\% de probabilidade de erro.

lote 6 e as menores nos lotes 1 e 3 . Além disso, ocorreram coeficientes de correlação significativos entre esses testes.

Os resultados obtidos indicaram que o procedimento mais promissor para a estratificação dos lotes de sementes de abóbora, em função do potencial fisiológico, apresentando coeficientes de correlação significativos com os demais testes que avaliaram a qualidade fisiológica das sementes, foi o período de três dias de exposição à baixa temperatura.

O período de frio recomendado pela pesquisa, para a maioria das espécies, é de sete dias a $10^{\circ} \mathrm{C}$ (CÍCERO \& VIEIRA, 1994). RODO et al. (1998) também verificaram que o teste de frio a $10^{\circ} \mathrm{C}$ por sete dias foi eficiente para avaliar o potencial fisiológico de sementes de tomate, apresentando correlação significativa com a emergência das plântulas em campo. Outros autores, PIANA et al. (1995) e TORRES et al.(1999), utilizando as mesmas condições de estresse, também observaram a eficiência desse teste em sementes de hortaliças como cebola e maxixe, respectivamente.

No entanto, no presente trabalho, os maiores períodos de exposição ao estresse ( sete e nove dias) provocado pela baixa temperatura, não indicou diferenças significativas entre os lotes e também apresentou menor coeficiente de correlação com os testes de germinação, com a primeira contagem de germinação, com o índice de velocidade de germinação, com o envelhecimento acelerado e com a emergência de plântulas.

O procedimento que proporcionou a melhor estratificação dos lotes em função do potencial fisiológico das sementes de abóbora variedade "Menina Brasileira" foi a utilização do período de três dias de exposição ao estresse provocado pela baixa temperatura.

\section{REFERÊNCIAS}

BRASIL. Ministério da Agricultura e Reforma Agrária. Regras para Análise de Sementes. Brasília : SNAD/CLAV, 1992. $365 \mathrm{p}$.

CASTELlane, D.P.; ARAUJO, J.A.C. Cultivos sem solo hidroponia. Jaboticabal-SP: Universidade Estadual Paulista, 1994. 43p.

CÍCERO, S.M.; VIEIRA, R.D. Teste de frio. In: VIEIRA, R.D.; CARVALHO, N.M. de. Testes de vigor em sementes. Jaboticabal-SP: FUNEP, 1994. p.151-164.

DIAS, D.C.F. et al. Comparação entre métodos para avaliação do vigor de sementes de pepino. In: CONGRESSO BRASILEIRO DE SEMENTES, 12., 2001, Curitiba. Anais... Londrina: Informativo ABRATES, 2001. V.11, n.2, p.204.

MAGUIRE, J.D. Spead of germination-aid in selection and evaluation for seedling emergence and vigour. Crop Science, Madison, v.2, n.1, p.176-177, 1962.

MARCOS FILHO, J. Pesquisa sobre vigor de sementes de hortaliças. Informativo ABRATES, Londrina, v.11, n.3, p.6375, 2001. 
PÁDUA, G.P. de. Vigor de sementes e seus possíveis efeitos sobre a emergência em campo e produtividade. Informativo ABRATES, Londrina, v.8, n.1/2/3, p.46-49, 1998.

PIANA, Z. et al. Avaliação fisiológica de sementes de cebola e sua relação com a produção de mudas vigorosas. Revista Brasileira de Sementes, Brasília, v.17, n.2, p.149-153, 1995.

RODO, A.B.et al. Testes de vigor na avaliação da qualidade fisiológica de sementes de tomate. Revista Brasileira de Sementes, Brasília, v.20, n.1, p.23-28, 1998.
RODO, A.B.; MARCOS FILHO, J. Envelhecimento acelerado e deterioração controlada na determinação do potencial fisiológico de sementes de cebola. Scientia Agricola, Piracicaba, v.60, n.3, p.465-469, 2003.

STORCK, L. et al. Esperimentação vegetal. Santa Maria: UFSM, 2000. 198p.

TORRES, S.B. et al. Correlação entre testes de vigor em sementes de maxixe. Pesquisa Agropecuária Brasileira, Brasília, v.34, n.6, p.1075-1080, 1999. 